\title{
Psychomotor and cognitive effects of 15-minute inhalation of methoxyflurane in healthy volunteers: implication for post-colonoscopy care
}

Authors

Institutions
Nam Q. Nguyen ${ }^{1,2}$, Jenna Burgess ${ }^{1}$, Tamara L. Debreceni ${ }^{1}$, Leanne Toscano ${ }^{1}$

Department of Gastroenterology and Hepatology. University of Adelaide, Adelaide, South Australia

${ }^{2}$ Discipline of Medicine, University of Adelaide, Adelaide, South Australia submitted 8. February 2016 accepted after revision 29. July 2016

\section{Bibliography}

Dol http://dx.doi.org/ 10.1055/s-0042-115409 Published online: 8.11.2016 Endoscopy International Open 2016; 04: E1171-E1177

(c) Georg Thieme Verlag KG Stuttgart . New York E-ISSN 2196-9736

\section{Corresponding author} Professor Nam Q Nguyen Department of

Gastroenterology, Royal Adelaide Hospital

North Terrace, Adelaide, SA 5000

Phone: +61 882225207

Fax: +61 882225885

quoc.nguyen@health.sa.gov.au
Background and study aims: Colonoscopy with portal inhaled methoxyflurane (Penthrox) is highly feasible with low sedation risk and allows earlier discharge. It is unclear if subjects can return to highly skilled psychomotor skill task shortly after Penthrox assisted colonoscopy. We evaluated the psychomotor and cognitive effects of 15-minute inhalation of Penthrox in adults. Patients and methods: Sixty healthy volunteers (18 to 80 years) were studied on 2 occasions with either Penthrox or placebo in a randomized, double-blind fashion. On each occasion, the subject's psychomotor function was examined before, immediately, 30, 60, 120, 180 and $240 \mathrm{~min}$ after a 15-minute inhalation of studied drug, using validated psychomotor tests (Digit Symbol Substitution Test (DSST), auditory reaction time (ART), eye-hand coordination (EHC) test, trail making test (TMT) and logical reasoning test (LRT).

\section{Introduction}

\section{$\nabla$}

Methoxyflurane is a halogenated ether that was used extensively for general anesthesia in the early 1960s [1]. At low dose, methoxyflurane exerts a uniquely powerful analgesic property without significant sedative effects [1-3]. This allows portable inhaled methoxyflurane (Penthrox, $3 \mathrm{~mL}$ per inhaler) to be used as a preferred analgesic in the Australasian community by ambulance services in the pre-hospital setting to provide pain relief without the need for an intravenous (IV) cannula [4-6]. Recently, methoxyflurane has also been increasingly used as analgesia for wound dressing for burn patients [7], prostate and bone marrow biopsy [8,9], computed tomography enteroclysis [10], and colonoscopy $[2,3]$. To date, the use of methoxyflurane at current dosage (up to $6 \mathrm{~mL}$ per day) has a good safety profile in over 5 million patients [11].
Results: Compared to placebo, a 15-minute Penthrox inhalation led to an immediate but small impairment of DSST $(P<0.001)$, ART $(P<0.001)$, EHC $(P<0.01)$, TMT $(P=0.02)$ and LRT $(P=0.04)$. In all subjects, the performance of all 5 tests normalized by 30 minutes after inhalation, and was comparable to that with placebo. Although increasing age was associated with a small deterioration in psychomotor testing performance, the magnitude of Penthrox effects remained comparable among all age groups.

Conclusions: In all age groups, a 15-minute Penthrox inhalation induces acute but short-lasting impairment of psychomotor and cognitive performance, which returns to normal within 30 minutes, indicating that subjects who have colonoscopy with Penthrox can return to highly skilled psychomotor skills tasks such as driving and daily work the same day.

In a recent large randomized trial, patients $(\mathrm{n}=$ 125) who were given a methoxyflurane inhaler during colonoscopy experienced good analgesia, liked being able to control drug administration, and found that methoxyflurane inhaler was pleasant and easy to use, as compared to patients who were sedated with midazolam and fentanyl $(n=126)$ [2]. Endoscopists who performed colonoscopies on patients who used a methoxyflurane inhaler found patients were more cooperative and had better postprocedure recall. Furthermore, the use of methoxyflurane was associated with a shorter recovery time (by at least 15 minutes), with no sedative effect or incidence of respiratory depression $[2,3]$. The potential clinical implication of these findings is that the use of methoxyflurane, instead of sedation for colonoscopy in clinical practice, can lead to earlier discharge and thus facilitate the workflow of endoscopy units. 
An unanswered issue related to the use of methoxyflurane in clinical settings is its impact on psychomotor function and the ability to drive or perform complex tasks, as the lack of adverse psychomotor effects from methoxyflurane may allow patients to drive, and even return to work on the day of colonoscopy. Given that colonoscopies are increasingly being performed for screening and surveillance purposes, the ability to return home or to work without carers would carry significant cost benefit and minimize work disruption. Currently, there are no data on the impact of inhaled methoxyflurane, or methoxyflurane in general, on the psychomotor function of humans. As there are no appropriate measures of within-subject variation and that information is not available from other published studies, the aims of this study were to evaluate the effects of inhaled methoxyflurane on psychomotor functions of healthy volunteers and the impact on psychomotor function in the aging after inhalation of methoxyflurane.

\section{Patients and methods \\ $\nabla$}

\section{Subjects}

Sixty $(n=60)$ healthy volunteers who were able to give informed consent, able to understand adequately use of the methoxyflurane (Penthrox) inhaler, and who had no contraindication to use of methoxyflurane were recruited. To assess the effects of methoxyflurane on different age groups, it was deemed necessary to have "equal representation" of subjects in different age groups, with 10 subjects per group arbitrarily divided as follows: $18-30$ years; 31-40 years; $41-50$ years; $51-60$ years; $61-70$ years and 71-80 years. Exclusion criteria were: (1) a history of significant alcohol ( $>40 \mathrm{~g} / \mathrm{d}$ for males, $20 \mathrm{~g} / \mathrm{d}$ for females) or narcotic use; (2) previous history of significant liver, cardiac or respiratory illnesses (i.e. ischemic heart disease, chronic obstructive pulmonary disease, chronic liver disease); (3) body mass index less than $19 \mathrm{~kg} / \mathrm{m}^{2}$; (4) any renal impairment; (5) previous possible allergy to the medication by the patient or a relative; (6) hypersensitivity to fluorinated agents; (7) previous head injury; (8) difficulty in following instructions (including language barrier); (9) concurrent use of any potential nephrotoxic drugs (e.g. aminoglycosides) or tetracyclines; and (10) personal or family history of malignant hyperthermia. Subjects were withdrawn from the study if they experience an adverse event or wished to discontinue.

The subjects were screened for suitability for the study based on the inclusion/exclusion criteria, either by in-person consultation or via a telephone conversation. Those who met the entry criteria were asked to have a screening visit for a blood test $(4 \mathrm{~mL})$ to check renal (urea and creatinine) and liver function. Only subjects who had normal renal and liver function were included in the study. Women of childbearing age were tested for pregnancy using a urine sample prior to commencement of the study, and excluded if they were pregnant. Adequate vision (with correction by glasses) was assessed by the 6-m reading test and normal was defined as 6/6 vision. Prior to involvement in the study, each subject was also asked to attend the Audio-Clinic Adelaide for a formal hearing test. For subjects between ages 71 and 80, a mini-mental test was performed as a screen for any overt cognitive impairment. Those with score less than 24 were excluded. The study was approved by the Human Research Ethics Committee and written informed consent was obtained from each subject prior to inclusion.

\section{Study protocol}

Healthy volunteers were evaluated in a randomized, placebocontrolled, crossover manner. Each subject was studied on 2 occasions with either placebo or methoxyflurane, separated by at least a 1-week duration and the order was randomized. Although "placebo" consisted of $3 \mathrm{~mL}$ of normal saline, the solution had the smell of methoxyflurane to "blind" the subject from distinguishing placebo from active methoxyflurane. Prior to the trial, a training session for the psychomotor tests was given to each subject, to minimize learning effects.

Randomization of the order of the studied drug and placebo was done in blocks of 10 using a computer program (GraphPad Software Inc., La Jolla, CA, USA). Results of the randomization were enclosed in envelopes labelled from subjects 1 to 60 . After successful recruitment, an envelope with a randomization letter was opened by an investigator who was not participating in the test delivery. The studied drug was prepared by this investigator, which was then given to the investigator who was administering the drug and tests, in a blinded fashion. The results of randomization were not revealed until the study was completed.

On each study occasion, subjects were studied in the morning and asked to not have any alcohol, illicit drugs or medications that could influence psychomotor function during the preceding 5 days. Subjects were also asked to have no more than 2 cups of tea or coffee, and not to have energy drinks or to take over-thecounter remedies with stimulant effects (such as pseudofat), during the 24 hours prior to the study. A battery of tests were then conducted to assess the subjects' psychomotor function at baseline ( $t=-15$ minutes). The subjects were then asked to inhale through a portable green inhaler containing either $3 \mathrm{~mL}$ of saline (placebo) or methoxyflurane over 15 minutes. The subjects were asked to take 10 inhalations of methoxyflurane at the beginning and 1 inhalation every 3 breaths thereafter for the rest of the 15 -minute duration. The "15-minute duration" was chosen, as that was the mean total colonoscopy time reported in our previous studies [2,3]. Psychomotor assessment was conducted immediately after ( $\mathrm{t}=0$ minutes), 30 minutes, 60 minutes, 120 minutes, 180 minutes and 240 minutes after the 15-minute inhalation.

\section{Psychomotor assessment}

A battery of 5 tests was used, all which had been previously validated and used extensively to assess psychomotor function of medications with analgesic and sedative properties. The tests included visual scanning, auditory reaction time, eye-hand coordination, mental flexibility, sustained attention, speed of information processing and memory [12-14].

1. The Digit Symbol Substitution Test (DSST), which assesses a number of different functions, including visual scanning, mental flexibility, logic reasoning, sustained attention, psychomotor speed, and speed of information processing [15-17], was a 1-minute test that required the subject to replace digits with corresponding symbols according to a digit-symbol code listed on the top of the paper [16]. The dependent measures were total number of symbols drawn and number of symbols drawn correctly.

2. The computerized logical reasoning test (LRT) consisting of true-false statements about the juxtaposition of the two letters A and B (e.g., A is preceded by B - true or false). The 1-miniute test assessed higher mental processes such as reasoning, logic, and verbal ability [18]. The dependent 
Table 1 Summary of the demographics and baseline characteristics of subjects.

\begin{tabular}{|lllllll|} 
& Ages $\mathbf{1 8 - 3 0}$ & Ages 31-40 & Ages 41-50 & Ages 51-60 & Ages 61-70 & Ages 71-80 \\
\hline Mean age & $22.8 \pm 1.0$ & $34.5 \pm 0.9$ & $44.2 \pm 0.9$ & $56.5 \pm 0.9$ & $64.3 \pm 0.8$ & $76.3 \pm 1.0$ \\
\hline Gender & $5 \mathrm{M}: 5 \mathrm{~F}$ & $3 \mathrm{M}: \mathbf{7} \mathrm{F}$ & $\mathbf{7 M}: 3 \mathrm{~F}$ & $5 \mathrm{M}: 5 \mathrm{~F}$ & $9 \mathrm{M}: 1 \mathrm{~F}$ & $7 \mathrm{M}: 3 \mathrm{~F}$ \\
\hline \% with normal visual acuity & $100 \%$ & $100 \%$ & $100 \%$ & $100 \%$ & $100 \%$ & $100 \%$ \\
\hline \% with normal hearing & $100 \%$ & $100 \%$ & $100 \%$ & $100 \%$ & $100 \%$ & $100 \%$ \\
\hline
\end{tabular}

measures were the total number of statements answered and number of statements answered correctly.

3. The 1-minute auditory reaction time (ART) test measures the time it took for subjects to react to 1050 -dBA computer-generated tones that were delivered at random time intervals [19]. The mean reaction time (in seconds) to depress a computer keyboard spacebar was the dependent measure.

4. The 1-minute eye-hand coordination (EHC) test requires the subject to track a randomly moving target (a circle) on the computer screen using a computer mouse [19]. The dependent measure was the duration of times that a small plus sign, which was controlled by the mouse, correctly followed the target circle, within $1 \mathrm{~cm}$ from the center of the circle.

5. The Trail Making Test (TMT) is primarily a test of motor speed and visual attention. In the first part, the subject's task is to quickly draw lines on a page connecting 25 consecutive numbers. In the second part, the subject must draw lines alternating between numbers and letters [20]. The dependent measure is the time it took for a person to connect all the letters and numbers in the correct order.

\section{Measured outcomes}

Primary endpoints were: (1) the differences in psychomotor functions between inhaled methoxyflurane and placebo in healthy volunteers; and (2) the intra-subject and inter-subject variability in these outcomes for planning a definitive equivalence study.

Secondary endpoints were: (1) the duration and severity of adverse impact of inhaled methoxyflurane on psychomotor functions in healthy volunteers; and (2) the influence of age on the effects of methoxyflurane on the psychomotor function in healthy subjects.

\section{Data analysis}

Data are expressed as mean ( \pm standard deviation (SD). Fisher's exact test was used for comparison of categorical data, and independent Student $t$-test for continuous data. The differences in psychomotor scores between methoxyflurane and placebo at different time points were compared using ANOVA analysis. Similarly, the differences over time between methoxyflurane and placebo were compared by ANOVA analysis. Analyses was performed using GraphPad Prism statistical software, version 6 (GraphPad Software Inc., La Jolla, CA, USA). A P value less than 0.05 was accepted as indicating statistical significance.

\section{Results}

$\nabla$

Sixty subjects were successfully studied over 12 months and the trial ended after the target number of volunteers was reached. The characteristics of the subgroups are summarized in Table 1. All subjects tolerated inhalation of placebo and methoxyflurane without any adverse events. There were no dif- ferences in the baseline assessments of DSST, ART, EHC, TMT, and LRT ( $\bullet$ Fig. 1) prior to methoxyflurane and placebo inhalation. Compared to placebo, a 15-minute methoxyflurane inhalation led to an immediate modest impairment of DSST $(P<0.001)$, ART $(P<0.001)$, EHC $(P<0.01)$, TMT $(P=0.02)$ and LRT $(P=0.04)$. While there were no significant changes in results of the DSST, ART, EHC and TMT tests between baseline and immediately after placebo, performances on the tests immediately after methoxyflurane were poorer than those at baseline ( $\bullet$ Table 2 ). For the LRT test, although the number of correct answers immediately after inhaled methoxyflurane was unchanged, the performance after placebo was better with significantly more correct answers ( Table 2). In all subjects, performance on all 5 tests normalized by 30 minutes after cessation of inhalation, and was comparable to that for placebo.

Increasing age was associated with a small deterioration in performance of psychomotor function tests. Except for hearing, the effects of methoxyflurane on other psychomotor functions remained comparable among all age groups ( $\bullet$ Fig. 2 ). The magnitude of methoxyflurane's effect on hearing was greater in the subjects older than age 60 and most pronounced immediately after inhalation of methoxyflurane. In all subjects, hearing returned to baseline by 30 minutes after inhalation.

\section{Discussion \\ $\nabla$}

Despite increasing use of inhaled methoxyflurane in clinical medicine, this is the first study that examined the effects of short-term use of methoxyflurane on psychomotor functions in humans. The current study demonstrated that 15-minute inhalation of methoxyflurane in healthy volunteers led to a small, acute deterioration in all aspects of psychomotor function but the effects lasted for less than 30 minutes after inhalation, and except for auditory reaction time, the psychomotor impact of methoxyflurane was equally observed in all age groups. Except for the DSST test, inhaled methoxyflurane induces an approximately $10 \%$ reduction in performance of highly skilled psychomotor tasks. Together our data indicated that subjects who use inhaled methoxyflurane as a mode of conscious analgesia for outpatient procedures such as colonoscopy or bone marrow or prostate biopsy can safely return the same day to tasks that require high psychomotor skills, such as driving and working.

Current recommendations from the British and ANZ Colleges of Anaesthetists are that after undergoing general anesthesia or IV sedation, a patient should not drive a car for 24 hours [21]. Driving is a complex task, and involves attention, information processing, judgement, sensorimotor skills, and perception [22]. Fitness to drive is assessed by psychomotor function tests, multiple sleep latency tests, and simulated driving tests [23]. Of these, psychomotor function tests are most commonly used to assess the "recovery time" for the subject's functions to return to baseline levels [23]. Tracking tasks, the pegboard test, the Maddox wing 

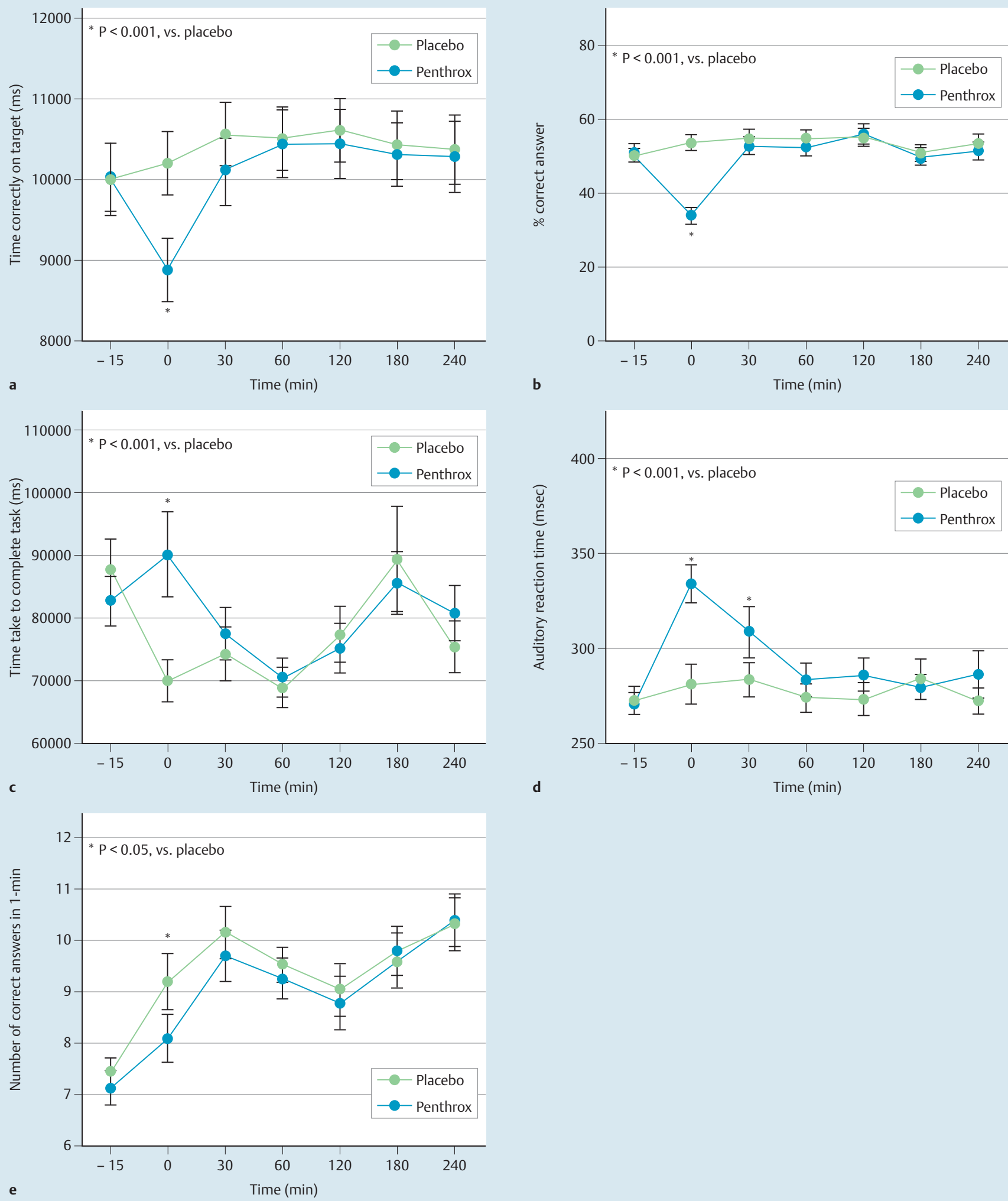

Fig. 1 Comparison of the overall effects of 15-minute inhaled methoxyflurane over placebo on a 1-minute eye-hand coordination (EHC); b Digital Symbol Substitution Test (DSST); c Trail Making Test (TMT); d 1-minute auditory reaction time (ART); and e logical reasoning test (LRT).

test, and perceptive accuracy tests appear to be the most sensitive psychomotor tests [23], all of which are included in the current study. Performance on psychomotor function testing has been shown to correlate with outcomes of driving simulation tests, which has been used as the gold standard to assess fitness to drive $[22,23]$. Based on these assessments, the longest psycho- motor recovery time period after administration of IV midazolam (maximum dose $0.15 \mathrm{mg} / \mathrm{kg}$ ) is 10 hours [24-26], fentanyl (maximum dose $2.5 \mathrm{mcg} / \mathrm{kg}$ ) is 6 hours to 8 hours [27,28], combination of propofol/midazolam/fentanyl is 8 hours to 10 hours [29, 30 ] and propofol alone is 2 hours [31]. These are the most commonly used IV sedative agents for colonoscopy, and thus, provid- 


\begin{tabular}{|c|c|c|c|c|}
\hline & Baseline & $\begin{array}{l}\text { Immediately after drug } \\
\text { administration }\end{array}$ & $\begin{array}{l}\% \text { change from baseline } \\
\text { measurements }\end{array}$ & $P$ value \\
\hline \multicolumn{5}{|c|}{ Inhaled methoxyflurane } \\
\hline $\begin{array}{l}\text { DSST (no. correct } \\
\text { answer in } 2 \mathrm{~min} \text { ) }\end{array}$ & $31.1 \pm 2.5$ & $18.8 \pm 4.7$ & $-34.4 \pm 17.2 \%$ & $P<0.0001$ \\
\hline ART (msec) & $301.3 \pm 23.4$ & $368.2 \pm 16.9$ & $+26.5 \pm 7.0 \%$ & $P<0.0001$ \\
\hline $\begin{array}{l}\text { EHC (time on target, } \\
\mathrm{msec} \text { ) }\end{array}$ & $5342 \pm 829$ & $4603 \pm 713$ & $-9.3 \pm 6.2 \%$ & $P<0.0001$ \\
\hline $\begin{array}{l}\text { TMT (time taken } \\
\text { to connect numbers } \\
\text { and letters, sec) }\end{array}$ & $83.3 \pm 3.8$ & $92.6 \pm 3.6$ & $+12.4+4.0 \%$ & $P=0.02$ \\
\hline $\begin{array}{l}\text { LRT (no. correct } \\
\text { answer in } 1 \mathrm{~min} \text { ) }\end{array}$ & $7.2 \pm 0.3$ & $7.7 \pm 0.4$ & $+6.2 \pm 3.8 \%$ & $P=0.21$ \\
\hline \multicolumn{5}{|c|}{ Placebo } \\
\hline $\begin{array}{l}\text { DSST(no. correct } \\
\text { answer in } 2 \mathrm{~min} \text { ) }\end{array}$ & $31.4 \pm 2.3$ & $34.5 \pm 4.9$ & $+3.4 \pm 6.2 \%$ & $P=0.74$ \\
\hline ART (msec) & $299.3 \pm 20.5$ & $305.9 \pm 19.3$ & $+3.2 \pm 3.9 \%$ & $P=0.68$ \\
\hline $\begin{array}{l}\text { EHC (time on target, } \\
\mathrm{msec} \text { ) }\end{array}$ & $5491 \pm 1036$ & $5921 \pm 897$ & $+4.3 \pm 5.1 \%$ & $P=0.09$ \\
\hline $\begin{array}{l}\text { TMT (time taken } \\
\text { to connect numbers } \\
\text { and letters, sec) }\end{array}$ & $83.8 \pm 4.1$ & $78.1 \pm 3.4$ & $-6.8+2.8 \%$ & $P=0.15$ \\
\hline $\begin{array}{l}\text { LRT (no. correct } \\
\text { answer in } 1 \mathrm{~min} \text { ) }\end{array}$ & $7.3 \pm 0.3$ & $8.9 \pm 0.5$ & $+28.3 \pm 7.7 \%$ & $P<0.0001$ \\
\hline
\end{tabular}

Table 2 Immediate impact of studied drugs on the performance of psychomotor tests in healthy volunteers.

DSST, Digital Symbol Substitution Test; ART, 1-minutes auditory reaction time; EHC, 1-minutes eye-hand coordination; TMT, Trail Making Test; LRT, logical reasoning test

ing a possible explanation for the recommendations not to drive for 12 to 24 hours after IV sedation, depending on the countries [32]. In our study, we have demonstrated that the longest psychomotor recovery time after administration of inhaled methoxyflurane was 0.5 hour, which is significantly shorter than the currently used IV sedatives. A recent study in Japan demonstrated that, of the 1183 patients who underwent colonoscopy with propofol alone (mean dose of 96.4 [40-200] mg) and drove home or to their office after colonoscopy, none had accidents or work incidents during the 24 hours after colonoscopy [31]. Together, our findings suggest that subjects who undergo colonoscopy with inhaled methoxyflurane should be able to drive or return to high-level psychomotor function tasks 1 hour after its administration.

The ability to drive or return to work within a few hours after colonoscopy has major health economic implications. A recent study found that over $90 \%$ of subjects who underwent a screening and surveillance colonoscopy took an average of 2.1 days off work for the procedure and the main reason was for precautionary measures after IV sedation [33]. Furthermore, $50 \%$ of the subjects had friends or family members who took days off from work because of the procedure. Thus, the indirect financial costs to society related to missed work for screening and surveillance colonoscopies should be taken into account, and could be minimized by avoiding use of IV sedation for colonoscopy. In addition to the significantly shorter recovery time from colonoscopy $[2,3]$, use of inhaled methoxyflurane for colonoscopy can prevent unnecessary time taken off from work and the associated costs to society. In fact, our findings indicate that subjects can return to work within 1 hour after the procedure.

Unsedated colonoscopy, which is a common approach in many countries in Southeast Asia and a few countries in Europe, has a number of other benefits. Even if sedation is safe, it requires an extra nurse and a team educated for monitoring, resulting in higher costs. Furthermore, the requirements for an escort and time burden of recovery from sedation are both barriers to the acceptance of screening colonoscopy. Improved acceptance of colonoscopy is important to allow full use of colonoscopy in cancer screening and prevention. Because most colonoscopies only cause minor discomfort, the procedure can be completed with appropriate analgesia, rather than sedation, in the majority of patients [34,35]. Undoubtedly, there is a place for unsedated colonoscopy, especially in areas involving screening and surveillance of colonic cancer.

Given that methoxyflurane is a volatile gas, the potential risk of occupational exposure will always be a concern, especially when acute high-dose exposure can lead to transient impairment of highly skilled psychomotor tasks. All available data related to occupational exposure to Penthrox are derived from studies performed in an Ambulance Service setting [1,11]. Even in the much smaller air space of the ambulance, studies have found that an 8-hour work day exposure is very small (ranging from 0.1 to $0.6 \mathrm{ppm}$ ) [11]. Based on 5 million units used in the pre-hospital paramedic setting, such minimal exposure has not been associated with any reported serious adverse events in health care workers [11]. This is in contrast to the inhaled concentration of at least $50 \mathrm{ppm}$ during active inhalation of Penthrox through the mouthpiece [11]. Given that endoscopy rooms are much larger ( 4 to 5 times the size of the ambulance) and have better ventilation systems, it is expected that the occupational exposure to Penthrox in endoscopy units would be substantially smaller (in the magnitude of 0.001 to $0.01 \mathrm{ppm}$ ) than that in the paramedic setting. Furthermore, the new Penthrox inhaler that is currently used in clinical practice has an activated carbon chamber, which can further reduce the concentration of exhaled methoxyflurane. Thus, it is expected that occupational exposure of methoxyflurane and its psychomotor impact on the endoscopic staff would be extremely low, if any. Because methoxyflurane has a characteristic fruity odor, any potential inadvertent leakage can easily be detected and the related adverse exposure readily avoided. The major strength of the current study is the sample size as well as the inclusion of all appropriate age groups who would be can- 
Original article
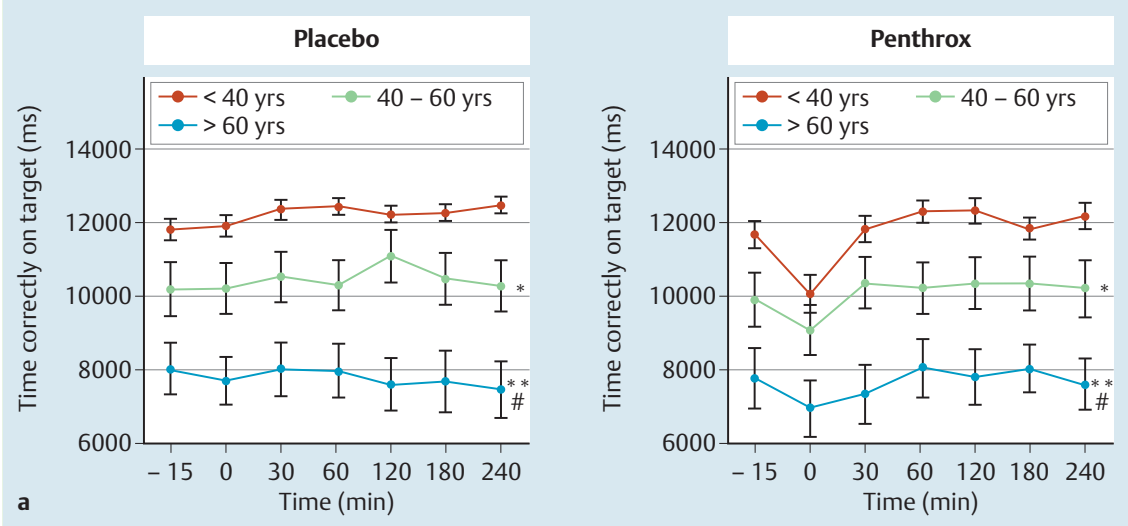

Fig.2 Impact of inhaled methoxyflurane and placebo, stratifying by age, on a 1 -minute eye-hand coordination (EHC); b Digital Symbol Substitution Test (DSST); c Trail Making Test (TMT); d 1-minute auditory reaction time (ART); and e logical reasoning test (LRT).
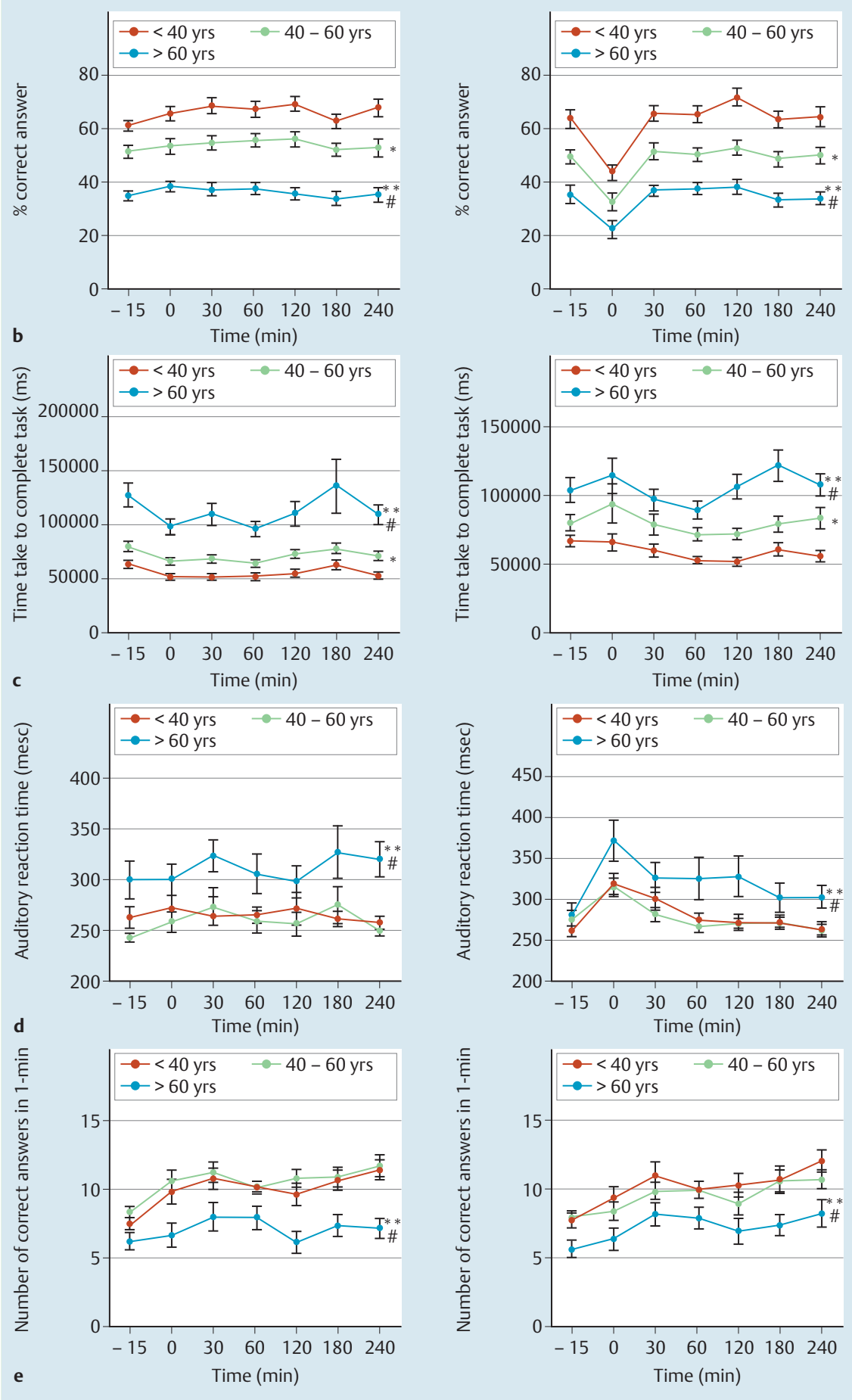

* $\mathrm{P}<0.05$, vs. $<40$ yrs $\quad * * \mathrm{P}<0.05$, vs. $<40$ yrs

\# $P<0.05$, vs. $40-60$ yrs 
didates for screening colonoscopy. However, there are a number of potential weaknesses, including selection bias toward patients who are healthy and with no serious medical conditions such as liver, renal or cardiorespiratory diseases, absence of physiological changes related to bowel preparation, and possibly, absence of sleep deprivation.

\section{Conclusion}

\section{$\nabla$}

In conclusion, a 15-minutes inhalation of methoxyflurane induces an acute but short-lasting impairment of psychomotor and cognitive performance in all age groups, and function returns to normal within 30 minutes after inhalation. These findings indicate that subjects who use inhaled Penthrox for colonoscopy can safely return, the same day, to tasks that require high-level psychomotor skills such as driving and work.

\section{Competing interests: None}

\section{References}

1 Grindlay J, Babl FE. Efficacy and safety of methoxyflurane analgesia in the emergency department and prehospital setting. Emerg Med Australas 2009; 21: 4-11

2 Nguyen NQ Toscano L, Matthew $L$ et al. Patient-controlled analgesia with inhaled methoxyflurane versus conventional endoscopistprovided sedation for colonoscopy: a randomized multi-center trial. Gastrointest Endosc 2013; 78: 892-901

3 Nguyen NQ Toscano L, Matthew L et al. Portable inhaled methoxyflurane for colonoscopy in patients with morbid obesity and/or obstructive sleep apnoea: a feasibility study. Endoscopy International 2015; 3: E487-493

4 Coffey F, Wright J, Hartshorn S et al. STOP! : a randomised, double-blind, placebo-controlled study of the efficacy and safety of methoxyflurane for the treatment of acute pain Emerg Med J 2014; 31: 613-618

5 Johnston S, Wilkes GJ, Thompson JA et al. Inhaled methoxyflurane and intranasal fentanyl for prehospital management of visceral pain in an Australian ambulance service. Emerg Med J 2011; 28: 57-63

6 Middleton PM, Simpson PM, Sinclair G et al. Effectiveness of morphine, fentanyl, and methoxyflurane in the prehospital setting. Prehosp Emerg Care 2010; 14: 439-447

7 Wasiak J, Mahar PD, Paul E et al. Inhaled methoxyflurane for pain and anxiety relief during burn wound care procedures: an Australian case series. Int Wound J 2014; 11: $74-78$

8 Spruyt 0 , Westerman D, Milner A et al. A randomised, double-blind, placebo-controlled study to assess the safety and efficacy of methoxyflurane for procedural pain of a bone marrow biopsy. BMJ Support Palliat Care 2014; 4: 342 -348

9 Huang S, Pepdjonovic L, Konstantatos A et al. Penthrox alone versus Penthrox plus periprostatic infiltration of local analgesia for analgesia in transrectal ultrasound-guided prostate biopsy. ANZ J Surg 2016; 86: $139-142$

10 Moss A, Parrish FJ, Naidoo P et al. Self-administered, inhaled methoxyflurane improves patient comfort during nasoduodenal intubation for computed tomography enteroclysis for suspected small bowel disease: a randomized, double-blind, placebo-controlled trial. Clin Radiol 2011; 66: 125-131

11 Australian Government, Department of Health, Therapeutic Goods Administration. Medicines Safety Update, Volume 5, Number 2, April 2014. Available from: https://www.tga.gov.au/publication-issue/medicines-safety-update-volume-5-number-2-april-2014. Accessed May 14,2015
12 Zacny J, Paice J, Coalson D. Characterising the subjective and psychomotor effects of carisoprodol in healthy volunteers. Pharmacol Biochem Behav 2011; 100: 138-143

13 Galinkin J, Janiszewski D, Young C et al. Subjective, psychomotor, cognitive and analgesic effects of subanesthetic concentrations of sevoflurance and nitrous oxide. Anesthesiology 1997; 87: 1002 - 1008

14 Janiszewski D, Galinkin J, Klock $A$ et al. The effects of subanesthetic concentrations of sevoflurane and nitrous oxide, alone and in combination, on analgesia, mood, and psychomotor performance in healthy volunteers. Anesth Analg 1999; 88: 1149-1154

15 Wetherell A. Performance tests. Environ Health Perspect 1996; 104 (Suppl. 02): 247-273

16 van Hoof JJ, Jogems-Kosterman BJ, Sabbe BG et al. Differentiation of cognitive and motor slowing in the Digit Symbol Test (DST): differences between depression and schizophrenia. J Psychiatr Res 1998; 32: 99103

17 Baddeley AD. Prior recall of newly learned items and the recency effect in free recall. Can J Psychol 1968; 22: 157-163

18 Nuotto EJ, Korttila KT. Evaluation of a new computerized psychomotor test battery: effects of alcohol. Pharmacol Toxicol 1991; 68: 360 - 365

19 Reitan RM. The relation of the trail making test to organic brain damage. J Consult Psychol 1955; 19: 393-394

20 Australian and New Zealand College of Anaesthetists. Endoscopy of the Airways. Review PS17; 1997

21 Mitchell MC. Alcohol-Induced Impairment of Central Nervous System Function: Behavioral Skills Involved in Driving. Journal of Studies on Alcohol 1985; Suppl. 10: 109-116

22 Tucker PF and Chilvers CR. Fitness to drive after intravenous sedation and general anaesthesia: a literature review. Australian Anaesthesia 2003: $27-40$

23 Hindmarch I, Subhan Z. The Effects of Midazolam in Conjunction with Alcohol on Sleep, Psychomotor Performance and Car Driving Ability. Internat J Clin Pharmacol Res 1983; 3: 323-329

24 Nuotto EJ, Korttila KT, Lichtor JL et al. Sedation and Recovery of Psychomotor Function After Intravenous Administration of Various Doses of Midazolam and Diazepam. Anesthesia Analgesia 1992; 74: 265-271

25 Gudgeon AC, Hindmarch I. Midazolam: Effects on Psychomotor Performance and Subjective Aspects of Sleep and Sedation in Normal Volunteers. Br J Clin Pharmacol 1983; 16 (Suppl. 01): 121S-126S

26 Ghoneim MM, Mewaldt SP, Thatcher JW. The Effect of Diazepam and Fentanyl on Mental, Psychomotor and Electroencephalographic Functions and Their Rate of Recovery. Psychopharmacologia (Berl.) 1975; 44: $61-66$

27 Manner T, Kanto J, Salonen M. Simple devices in differentiating the effects of buprenorphine and fentanyl in healthy volunteers. Europ J Clin Pharmacol 1987; 31: 673-676

28 Larson LE, Gupta A, Ledin T et al. Psychomotor recovery following propofol or isoflurane anaesthesia for day-care surgery. Acta Anaesthesiol Scand 1992; 36: 276-282

29 Milligan KR, O'Toole DP, Howe JP et al. Recovery from Outpatient Anaesthesia: A Comparison of Incremental Propofol and Propofol-Isoflurane. Br J Anaesthesia 1987; 59: 1111-1114

30 Kestin IG, Harvey PB, Nixon C. Psychomotor Recovery after Three Methods of Sedation during Spinal Anaesthesia. Br J Anaesthesia 1990; 64: $675-681$

31 Horiuchi A, Nakayama Y, Kajiyama $M$ et al. Safety and effectiveness of propofol sedation during and after outpatient colonoscopy. World J Gastroenterol 2012; 18: 3420-3425

32 Dong MH, Kalmaz D, Savides TJ. Missed work related to mid-week screening colonoscopy. Dig Dis Sci 2011; 56: 2114-2119

33 Leung FW, Aljebreen AM, Brocchi E et al. Sedation-risk-free colonoscopy for minimizing the burden of colorectal cancer screening. World J Gastrointest Endosc 2010; 2: 81 - 89

34 Leung FW. Is there a place for sedationless colonoscopy? J Interv Gastroenterol 2011; 1: 19-22

35 Paggi S, Radaelli F, Amato $A$ et al. Unsedated colonoscopy: an option for some but not for all. Gastrointest Endosc 2012; 75: 392-398 